\title{
Utilization of Sewage Sludge Ash in Self-Compacted Concrete
}

\author{
Siham Al Shanti ${ }^{1}$, Amr El-Dieb ${ }^{1}$, Munjed A. Maraqa ${ }^{1}$ \\ ${ }^{1}$ United Arab Emirates University, Al Ain, United Arab Emirates \\ 201250567@uaeu.ac.ae; amr.eldieb@uaeu.ac.ae; \\ m.maraqa@uaeu.ac.ae
}

\begin{abstract}
Rapid urbanization throughout the world resulted in a considerable amount of sewage sludge, which is commonly considered a great environmental concern. Also, the rapid growth of self-compacting concrete (SCC) marks a significant milestone in enhancing the construction industry's effectiveness. Hence, an experimental program was carried out to study self-compacting concrete (SCC) properties incorporating sewage sludge ash (SSA) as a partial replacement of cement. Mixes were prepared with two percentages $(0$ and $20 \%$ by mass) of SSA as partial replacement of cement. The slump flow, $\mathrm{T}_{50}$ flow time, J-ring, and V-funnel were evaluated for the fresh SCC. Hardened properties of SCC were assessed by measuring compressive strength, rapid chloride penetration, bulk electrical resistivity, water absorption rate (i.e., sorptivity), and water permeability. Test results indicated that SCC made with SSA must incorporate a higher dosage of admixtures than the control mix to achieve satisfactory workability, passing ability, and viscosity. SSA contributed to the concrete mix's late strength development and led to durable concrete with a low chloride permeability resistance and a high electrical resistivity. There was a negligible increase in the rate of water absorption and water permeability. However, the water absorption rate and permeability are expected to reduce with age due to the pozzolanic reaction of SSA. SSA was found to have the potential to be used as partial cement replacement in making SCC, which could lead to a profound impact on solid waste management and sustainable development in the construction industry.
\end{abstract}

Keywords: Self-Compacted Concrete, Sewage Sludge Ash, Sustainability, Fresh Stage, Hardened Stage, Durability

\section{Introduction}

Self-compacting concrete (SCC) is an innovative concrete and one of the concrete industry's latest achievements. It flows readily to fill the formwork and compact under its weight without requiring any compaction or vibration [1]. SCC differs from conventional concrete in including a higher proportion of cement, mineral admixtures, fine aggregates, superplasticizer, and lower content of coarse aggregates [2]. Furthermore, supplementary cementing materials (SCM) in SCC are essential differences between SCC and conventional concrete. While using SCM in SCC improves the mechanical, durability, and long-term properties of concrete, utilizing such wastes in making concrete plays a significant role in minimizing the amount of the $\mathrm{CO}_{2}$ production associated with manufacturing ordinary Portland cement (OPC) [3]. Therefore, one of the most global encouragements for sustainable development and a substantial waste management challenge is introducing industrial waste as supplementary cementing materials in making concrete [4].

Due to the rapid increase in the population worldwide, an enormous amount of sewage sludge is generated; it is declared that each year around 75 million tons of sewage sludge is produced in most of the developed and developing countries [5]. Although sewage sludge's incineration minimizes its volume by approximately $70 \%$ to $90 \%$, it is not the final waste treatment stage. The final disposal of the produced sewage sludge ash (SSA) is not an easy task due to its negative environmental impact. Hence, due to limited landfill spaces and the environmental restrictions in landfill areas, managing such waste is considered a major issue in several countries [6]. Previous research reported that the use of SSA in developing sustainable construction material would be a practical approach to preserving natural resources, reducing $\mathrm{CO}_{2}$ emissions, and lowering the costs of SSA management [7]. Several researchers worldwide studied the utilization of SSA in the construction industry, such as bricks [8], conventionally vibrated mortar and concrete [9], lightweight aggregate [10], and asphalt paving material [11].

In many cases, one of the most significant applications is the reuse of SSA as SCM in concrete production. Previous studies have shown that the mortars incorporating SSA as a partial replacement of OPC exhibited good mechanical properties [12], without a decrease in compressive strengths. Pinarli and Kaymal [13] and Ing et al. [14] reported that mortars containing up to $10 \%$ of SSA as a partial replacement of OPC showed similar or greater strength values than the control mix. However, 
strength reduction was observed when the percentage of replacement was increased to $25 \%$ and $50 \%$, and the reduction decreased over time [15]. Lin et al. [16] found that finer SSA particles exhibit greater pozzolanic activity, resulting in higher compressive strength of mortars. When the cement was replaced with SSA in amounts of up to $10 \%$ by mass, mortar corrosion performance was comparable to the control mortar's behavior [17]. Regarding the fresh stage of concrete, there was a notable decrease in workability for concrete incorporating SSA as partial replacement of cement because of its irregular morphology and porous structure. However, the addition of plasticizing agents could be used to overcome this reduction [18]. Although several studies have been done on the physical properties and mechanical performance of concrete using SSA, relatively little attention has been paid to the effect of SSA on concrete durability and the implementation of SSA in high-performance concrete (HPC) and SCC.

This study aimed to investigate the effect of introducing SSA as a partial replacement of OPC on the performance of SCC in its fresh and hardened stages. This will provide better knowledge on utilizing SSA in an environmentally friendly and sustainable way by developing a green SCC with a minimal impact on the environment over its entire life cycle.

\section{Materials and Experimental Procedures \\ 2.1. Materials}

In this study, OPC conforming to ASTM C150 - Type 1 was used. Ground SSA incinerated at $900{ }^{\circ} \mathrm{C}$ for 2 hours was used as supplementary cementing material. The chemical composition, mineralogical configuration, and reactivity of the used SSA were assessed in a previous study and summarized in Table 1 and Fig. 1 [19]. Natural crushed stone with a nominal size of $9.5 \mathrm{~mm}$ (3/8 in.) and a specific gravity of 2.67 was used as a coarse aggregate. The fine aggregates were crushed natural stone sand with fineness modulus of 3.6 and a specific gravity of 2.64, and dune sand with fineness modulus of 0.9 and a specific gravity of 2.63. Superplasticizer (SP) and viscosity modifying admixtures (VMA) were used to enhance the mixtures' flowability and viscosity, respectively.

Table 1: SSA chemical composition as a mass percentage.

\begin{tabular}{lllllllllllll}
\hline $\mathrm{SiO}_{2}$ & $\mathrm{CaO}$ & $\mathrm{P}_{2} \mathrm{O}_{5}$ & $\mathrm{SO}_{3}$ & $\mathrm{Al}_{2} \mathrm{O}_{3}$ & $\mathrm{Fe}_{2} \mathrm{O}_{3}$ & $\mathrm{MgO}$ & $\mathrm{K}_{2} \mathrm{O}$ & $\mathrm{TiO}_{2}$ & $\mathrm{ZnO}$ & $\mathrm{SrO}$ & $\mathrm{MnO}$ & $\mathrm{CuO}$ \\
\hline 25.2 & 23.5 & 21.3 & 4.5 & 9.6 & 6.2 & 7.0 & 1.2 & 0.70 & 0.25 & 0. & 0.13 & 0.10 \\
\hline
\end{tabular}

\subsection{Mixture Design}

As summarized in Table 2, one control mixture with 0\% replacement of SSA and two SCC mixtures with SSA was designed with a constant w/c ratio of 0.35 and a total cementitious content of $500 \mathrm{~kg} / \mathrm{m} 3$. These parameters were kept constant to eliminate their effects on the results and inspect the effect of SSA on the produced SCC performance. The control mixture contained only OPC, whereas the other mixtures incorporated 20\% SSA as a partial replacement of OPC on the cementitious content's total mass basis. For the first two SCC mixtures (control mix and SSA1-20), the fine aggregate-to-total aggregate ratio, by mass, was set at 0.50 , and the dune sand-to-total fine aggregate ratio was set at 0.55 . Furthermore, the dosage of SP and VMA for these two mixtures was set at $1.6 \%$ and $0.35 \%$, respectively, by weight of the OPC or the OPC+SSA. The trial SCC mix's workability containing $20 \%$ SSA as a partial replacement of cement (SSA1-20) did not meet the minimum requirement to be classified as an SCC. Therefore, the third mix (SSA2-20) was modified to have a dune sand-to-total-fine aggregate ratio of 0.45 . Moreover, the admixture dosages were increased to $2.1 \%$ and $0.5 \%$ for both SP and VMA, respectively, by weight of OPC+SSA. In SCC production, the mixing efficiency, mixer type, and mixing sequence are significant factors affecting SCC properties [20]. Hence, the same procedure for batching and mixing were followed to achieve the same homogeneity and uniformity in all mixtures. 


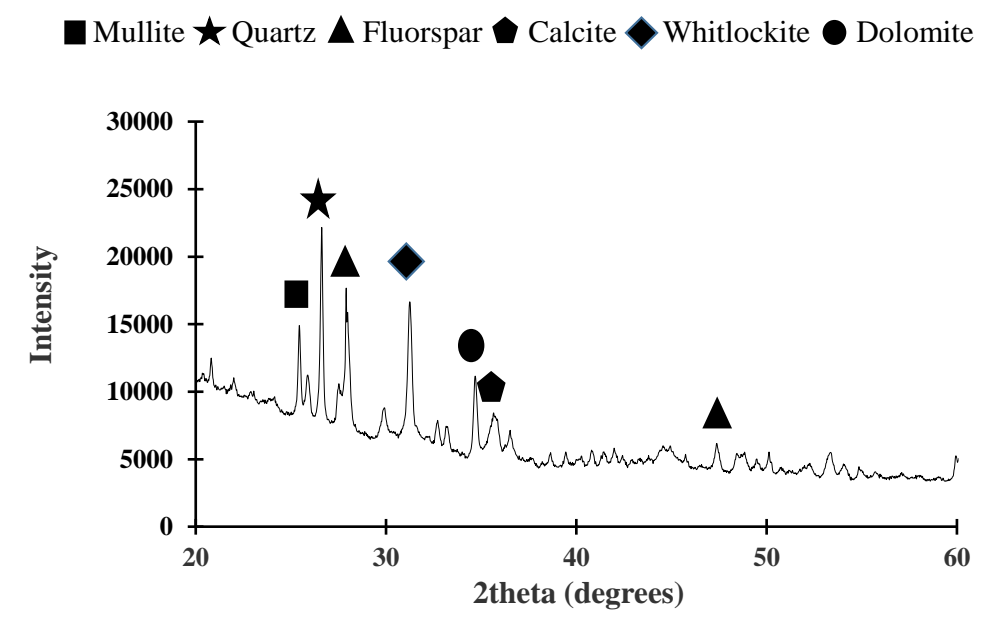

Fig. 1: Mineralogical configuration of used SSA.

Table 2: Mix proportions of SCC mixtures without and with SSA $\left(\mathrm{kg} / \mathrm{m}^{3}\right)$.

\begin{tabular}{|c|c|c|c|c|c|c|c|c|c|}
\hline \multirow{2}{*}{ Mix } & \multirow{2}{*}{ OPC } & \multirow{2}{*}{ SSA } & \multirow{2}{*}{$\mathrm{CA}$} & \multicolumn{2}{|c|}{ FA } & \multirow{2}{*}{ Water } & \multirow{2}{*}{$\mathrm{SP}$} & \multirow{2}{*}{ VMA } & \multirow{2}{*}{$\mathrm{w} / \mathrm{c}$} \\
\hline & & & & DS & $\mathrm{CS}$ & & & & \\
\hline Control mix & 500 & --- & 871 & 479 & 392 & 175 & 8.3 & 1.75 & 0.35 \\
\hline SSA1-20 & 400 & 100 & 853 & 469 & 384 & 175 & 8.3 & 1.75 & 0.35 \\
\hline SSA2-20 & 400 & 100 & 853 & 384 & 469 & 175 & 10 & 2.5 & 0.35 \\
\hline
\end{tabular}

\subsection{Test Methods}

\subsubsection{Fresh Concrete Properties}

The produced fresh SCC mixtures' properties were assessed by slump flow, $\mathrm{T}_{50}, \mathrm{~V}$-funnel, and J-ring tests. The first three tests were conducted according to suggested procedures by EFNARC 2005 [21], whereas the J-ring test was performed according to ASTM C162. The slump flow test evaluated the unrestricted flowability of SCC while the time to reach a flow diameter of $50 \mathrm{~cm}\left(\mathrm{~T}_{50}\right)$ assessed the SCC viscosity. The V-funnel test was conducted to measure the viscosity and the filling characteristics of the SCC mixtures by forcing the SCC concrete to flow through a small cross-section and bounded space. The J-ring test was conducted to evaluate the SCC mixtures' passing ability (i.e., how the mixture would function in a restricted space similar to reinforcing bars). The diameter spread of concrete through the J-ring apparatus was recorded. The ability of concrete to pass through steel reinforcement was examined by calculating the difference in diameters between the slump flow and the J-ring tests. Concrete mixtures were assessed as SCC mixtures according to the recommendation of EFNARC guidelines [21].

\subsubsection{Compressive Strength and Durability}

The average compressive strength of three cube specimens (i.e., 100x100x100 mm) was measured at 7 and 28 days of curing for all mixtures. The mixtures' durability was evaluated by the rapid chloride penetration test (RCPT), bulk electrical resistivity, water absorption rate, and water permeability. All durability tests were conducted at 28 days of curing for all mixtures. The RCPT assessed the resistance of concrete to chloride-induced corrosion. The test was performed according to the ASTM C1202. The bulk electrical resistivity test was conducted according to the ASTM C1876. The electrical resistivity values judged corrosion protection for steel bars embedded in concrete as per ACI 222R-01 [22]. The water absorption rate 
of concrete (i.e., sorptivity $\mathrm{S}$ in $\mathrm{mm} / \mathrm{s}^{1 / 2}$ ) was measured according to the ASTM C1585. The water permeability through the concrete was conducted using a constant water pressure head (i.e., 35 bars) and measuring the outflow rate.

\section{Results and Discussion}

\subsection{Self-Compacted Concrete Fresh Properties}

Test results of the fresh properties for all SCC mixtures are presented in Table 3. As shown in Fig. 2 (a) and (b), and the values obtained from the slump flow, $\mathrm{T}_{50}$ and J-ring tests (Table 3), the inclusion of $20 \%$ SSA without any modifications to the mixture (SSA1-20) caused a significant decrease in workability, $\mathrm{T}_{50}$ flow time, and passing ability of the mix. This is due to SSA particles' irregular morphology and inner porosity, which played a significant role in absorbing part of the mixing water [12]. Figure 2(c) shows the modified SCC mixture, including 20\% SSA (SSA2-20). It was observed that increasing the admixture's dosage and modifying the mixture proportions when introducing SSA enhanced the flowability behavior and the mixture's passing ability. This behavior was also observed by Monzó et al. [18]. The modification of the mixture resulted in a slump value of SSA2-20 higher than the control mix. Also, a reduction of $\mathrm{T}_{50}$ flow time from 4.32 seconds in the control mix to 2.09 seconds in SSA2-20 was observed. Both slump flow and $\mathrm{T}_{50}$ test results indicated that the modified SCC mixture, including 20\% SSA as a partial replacement of OPC, exhibited better flowability characteristics than the control mix, and it can be designated as an SCC mix. Although SSA2-20 contained a higher VMA dosage than the control mix, an increase in the viscosity of SSA2-20 was observed. However, it is within the acceptable range as per EFNARC guidelines [21]. This implies that the inclusion of SSA led to more viscous concrete, thus improving the mix's segregation resistance property. The increments of SP and VMA dosages contributed to enhancing the mixture's passing ability, as shown in Fig. 3. SSA220 exhibited no visible blocking suggesting that it would perform very well in highly congested reinforced concrete structures or small-sized sections.

\subsection{Compressive Strength}

The mean values of the compressive strength of the hardened SCC control mixture (0\% SSA) and the SCC mixture incorporating 20\% of SSA (SSA-2-20) at 7 and 28 days of curing are summarized in Table 4. For both mixtures, the compressive strength increased with age. It was observed that the compressive strength slightly decreased with the addition of $20 \%$ SSA as a partial replacement of OPC. The reduction of strength caused by the addition of SSA at an early age (7 days) was approximately $9.4 \%$. While at a late age, a reduction of $2 \%$ was recorded. The decrease in early strength of SSA220 might be partly due to the decrease in the main binder content (i.e., cement) and using SSA characterized with low pozzolanic activity $[19,23]$. The compressive strength development at 28 days for the SSA2-20 mixture could be attributed to the continuation of the cement hydration and the pozzolanic reaction of the SSA. Therefore, it can be concluded that SSA plays an active role in compressive strength development and a positive strength gain with age. It will be interesting to investigate the change in the strength of the SCC modified with SSA versus the control SCC at late ages (i.e., at 56 or 90 days)

Table 3: SCC fresh properties test results.

\begin{tabular}{ccccc}
\hline Mix & $\begin{array}{c}\text { Slump flow } \\
\text { diameter }(\mathrm{mm})\end{array}$ & $\begin{array}{c}\mathrm{T}_{50} \\
(\text { seconds })\end{array}$ & $\begin{array}{c}\text { J-ring diameter } \\
(\mathrm{mm})\end{array}$ & $\begin{array}{c}\text { V-funnel time } \\
\text { (seconds) }\end{array}$ \\
\hline Control mix & 730 & 4.32 & 720 & 7.59 \\
\hline SSA1-20 & 588 & 7.48 & 498 & $>12$ \\
\hline SSA2-20 & 760 & 2.09 & 745 & 10.54 \\
\hline
\end{tabular}



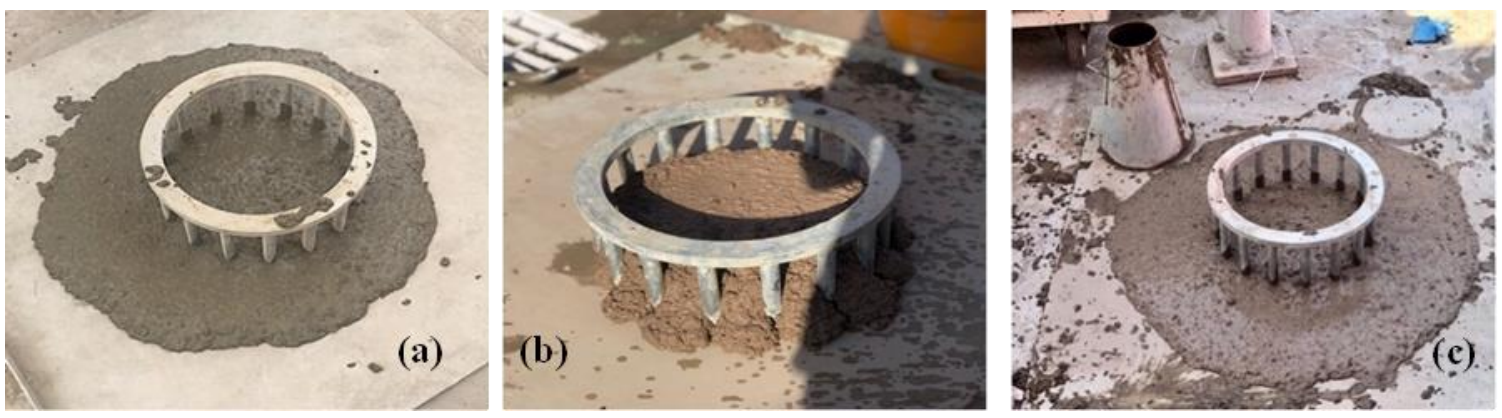

Fig. 2: J-ring test for SCC mixtures (a) control, (b) SSA1-20 and (c) SSA2-20.

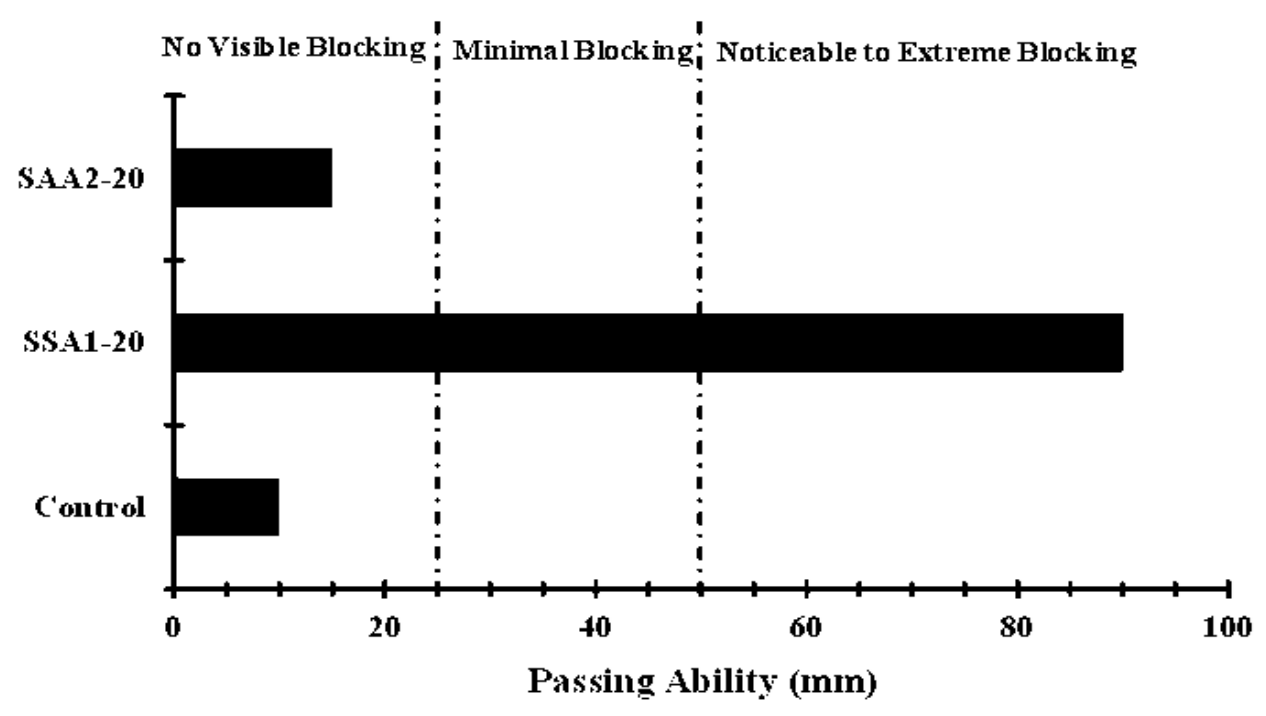

Fig. 3: Passing ability of SCC mixtures.

Table 4: Compressive strength at 7 days and 28 days of curing.

\begin{tabular}{ccc}
\hline \multirow{2}{*}{ Mixture } & \multicolumn{2}{c}{ Compressive strength $(\mathrm{MPa})^{*}$} \\
\cline { 2 - 3 } & 7 days & 28 days \\
\hline Control mix & $57.4(3.15)$ & $66.7(2.08)$ \\
\hline SSA2-20 & $52.0(2.39)$ & $65.3(0.89)$ \\
\hline * Values in parenthesis are the coefficient of variation
\end{tabular}

\subsection{Durability}

Durability tests were conducted at 28 days of age, and the test results are listed in Table 5. It is clear from the RCPT results that incorporating SSA in the concrete mixtures resulted in decreasing the total passed charged (i.e., 35\% reduction); thus, reducing the chloride penetration through concrete and improving the resistance of the concrete to chloride-induced corrosion. According to ASTM C 1202 penetration classification, the SSA2-20 mixture is classified as low chloride penetration, while the control mix (0\% SSA) is classified as moderate chloride penetration. The enhancement of the resistance to chloride penetration can be related to the pozzolanic reaction of SSA. Similarly, it was observed that the addition of SSA resulted in a slight increase in the bulk resistivity of the mixture by approximately $2.8 \%$ at 28 days of age. Generally, the 
higher the concrete resistivity, the greater the corrosion endurance is [22]. Hence, the addition of SSA produced highperformance SCC with higher corrosion protection than the control mix. However, according to ACI 222R-01, both mixtures are classified to have high corrosion protection for steel bars embedded in concrete. As shown in Table 5, the rate of water absorption (i.e., sorptivity) for SSA2-20 was comparable to the control mix, indicating that the addition of SSA does not have a noticeable effect on the rate of water absorption of concrete. Table 5 shows that the water permeability coefficient for both mixes was relatively similar and low. Since water permeability is one of the main factors affecting the durability of concrete [24], the results obtained indicated that both mixes have high durability. Since SSA exhibited late pozzolanic activity [19], the measured durability indices are expected to improve at later ages (i.e., 56 or 90 days of age). This would increase the concrete's ability to endure the ingress of aggressive species from the surrounding environment.

Table 5: Durability test results.

\begin{tabular}{ccc}
\hline Property* & Control Mixture & SSA2-20 \\
\hline RCPT $($ coulombs $)$ & $2931(11.4)$ & $1904(15.3)$ \\
\hline Resistivity $(\mathrm{k} \Omega . \mathrm{cm})$ & $10.6(0.74)$ & $10.9(3.7)$ \\
\hline Sorptivity $\left(\mathrm{mm} / \mathrm{s}^{1 / 2}\right)$ & $0.017(31.5)$ & $0.021(31.7)$ \\
\hline Water Permeability $(\mathrm{m} / \mathrm{s})$ & $8.2 \times 10^{-11}(43.8)$ & $8.3 \times 10^{-11}(29.7)$ \\
\hline \multicolumn{2}{c}{ Values in parenthesis are the coefficient of variation }
\end{tabular}

\section{Conclusions}

Utilizing SSA in the concrete industry will help solve the SSA disposal issue while providing productive use. This study's main aim was to reuse SSA in producing sustainable high-performance SCC by evaluating SSA's effect on both the fresh and hardened properties of the produced concrete. From the conducted experimental work, the following conclusions can be drawn:

1. The incorporation of $20 \%$ SSA as partial replacement of OPC resulted in reducing the workability, passing ability, and viscosity of the SCC mix if the concrete mixture is not adjusted. It was mandatory to adjust the mix's fine powder content and increase the SP and the VMA dosages in the mix. Adjustment of the concrete mixture and incorporation of $20 \%$ SSA significantly improved the fresh SCC properties (i.e., higher flowability, better passing ability, and higher viscosity).

2. At an early age (i.e., 7 days), the use of $20 \%$ of SSA as a partial replacement of OPC resulted in decreased SCC compressive strength. However, at late ages, SCC's compressive strength value incorporating SSA was comparable to the control mix due to SSA's late pozzolanic activity. The inclusion of SSA resulted in improving investigated durability characteristics of the produced SCC, including the total passed charged through concrete specimens and the bulk electrical resistivity. It is expected that the performance of the SCC incorporated SSA increases at later ages.

3. At 28 days of curing, there was no noticeable effect on the rate of water absorption and water permeability when SSA was used as partial cement replacement. However, it is expected to decrease with age due to the pozzolanic activity of the SSA.

4. SSA showed a promising potential to be used as an SCM to produce high-performance SCC; therefore, contributing to the sustainable development of construction materials by reducing the negative impact arising from SSA disposal and cement manufacturing.

\section{Acknowledgment}

The UAEU-UPAR Research Grant \#31N377 provided funding for this study. The authors would like to thank Al Saad Wastewater Treatment Plant in Al Ain, UAE, for providing sewage sludge samples. The help of the Concrete Lab engineer 
and technician in conducting the work is very much appreciated. The authors would like to thank ASTM Project Grant Award 2019 and the ACI Foundation - ACI Middle East Fellowship 2020-2021 awarded to the M.Sc. student.

\section{References}

[1] H. Okamura and M. Ouchi, "Self-compacting concrete," J. Adv. Concr. Technol., vol. 1, no. 1, pp. 5-15, 2003.

[2] R. Sharma and R. A. Khan, "Influence of copper slag and metakaolin on the durability of self-compacting concrete," J. Clean. Prod., vol. 171, pp. 1171-1186, 2018.

[3] R. S. Ahari, T. K. Erdem and K. Ramyar, "Permeability properties of self-consolidating concrete containing various supplementary cementitious materials," J. Constr. Build. Mater., vol. 79, pp. 326-336, 2015.

[4] E. Uyarra and S. Gee, "Transforming urban waste into sustainable material and energy usage: The case of Greater Manchester (UK)," J. Clean. Prod., vol. 50, pp. 101-110, 2013.

[5] S. Chakraborty, B. W. Jo, J. H. Jo and Z. Baloch, "Effectiveness of sewage sludge ash combined with waste pozzolanic minerals in developing sustainable construction material: An alternative approach for waste management,". J. Clean. Prod., vol. 153, pp. 253-263, 2017.

[6] M. Lundin, M. Olofsson, G. J. Pettersson and H. Zetterlund, "Environmental and economic assessment of sewage sludge handling options," J. Resour. Conserv. Recycl., vol. 41, no. 4, pp. 255-278, 2004.

[7] P. Pavšič, A. Mladenovič, A. Mauko, S. Kramar, M. Dolenec, E. Vončina and P. Bukovec, " Sewage sludge/biomass ash based products for sustainable construction," J. Clean. Prod., vol. 67, pp. 117-124, 2014.

[8] B. Wiebusch, M. Ozaki, H. Watanabe and C. F. Seyfried, "Assessment of leaching tests on construction material made of incinerator ash (sewage sludge): investigations in Japan and Germany," J. Water Sci. Technol., vol. 38, no. 7, pp. 195-205, 1998.

[9] J. H. Tay, W. K. Yip and K. Y. Show, "Clay-blended sludge as lightweight aggregate concrete material," J. Environ. Eng., vol. 117, no. 6, pp. 834-844, 1991.

[10] J. Chiou, K.S. Wang, C. H. Chen and Y. T. Lin, "Lightweight aggregate made from sewage sludge and incinerated ash," J. Waste Manag., vol. 26, no. 12, pp. 1453-1461, 2006.

[11] C. F. Lin, C. H. Wu and H. M. Ho, "Recovery of municipal waste incineration bottom ash and water treatment sludge to water-permeable pavement materials," J. Waste Manag., vol. 26, no. 9, pp. 970-978, 2006.

[12] J. Monzó, J. Paya, M. V. Borrachero and A. Córcoles, "Use of sewage sludge ash (SSA)-cement admixtures in mortars," J. Cem. Concr. Res., vol. 26, no. 9, pp. 1389-1398, 1996.

[13] V. Pinarli and G. Kaymal, "An innovative sludge disposal option-reuse of sludge ash by incorporation in construction materials," J. Environ. Technol., vol. 15, no. 9, pp. 843-852, 1994.

[14] D. S. Ing, S. C. Chin, T. K. Guan and A. Suil, "The use of sewage sludge ash (SSA) as partial replacement of cement in concrete," ARPN J. Eng. Appl. Sci., vol. 11, no. 6, pp. 3771-3775, 2016.

[15] M. Cyr, M. Coutand and P. Clastres, "Technological and environmental behavior of sewage sludge ash (SSA) in cement-based materials," J. Cem. Concr. Res., vol. 37, no. 8, pp. 1278-1289, 2007.

[16] K. L. Lin, W. C. Chang, D. F. Lin, H. L. Luo and M. C. Tsai, "Effects of nano-SiO2 and different ash particle sizes on sludge ash-cement mortar," J. Environ. Manage., vol. 88, no. 4, pp. 708-714, 2008.

[17] E. G. Alcocel, P. Garcés, J. J. Martínez, J. Payá and L. G. Andión, "Effect of sewage sludge ash (SSA) on the mechanical performance and corrosion levels of reinforced Portland cement mortars," Materiales de Construcción, vol. 56, no. 282, pp. 31-43, 2006.

[18] J. Monzó, J. Payá, M. V. Borrachero and I. Girbés, "Reuse of sewage sludge ashes (SSA) in cement mixtures: the effect of SSA on the workability of cement mortars," J. Waste Manag., vol. 23, no. 4, pp. 373-381, 2003.

[19] S. AlShanti, A. S. El-Dieb and M. A. Maraqa, "Characterization of sewage sludge ash as affected by different incineration temperature and time," in Proceedings of the SCTM5 the $5^{\text {th }}$ International Conference on Sustainable Construction Materials and Technologies, Coventry University, Coventry, UK. 2019 (http://scmt.org.uk/)

[20] K. H. Khayat, J. Bickley and M. Lessard, "Performance of self-consolidating concrete for casting basement and foundation walls," ACI Mater. J., vol. 97, no. 3, pp. 374-380, 2000. 
[21] EFNARC (European Federation of National Trade Associations Representing Producers and Applicators of Specialist Building Products), "The European guidelines for self-compacting concrete: Specification, production, and use," Hampshire, U.K., 68p., 2005 [Online] Available http://www.efnarc.org/pdf/SCCGuidelinesMay2005.pdf

[22] ACI 222R-01, "Protection of Metals in Concrete Against Corrosion," American Concrete Institute, 41p., 2008.

[23] S. C. Pan, D. H. Tseng, C. C. Lee and C. Lee, "Influence of the fineness of sewage sludge ash on the mortar properties," J. Cem. Concr. Res., vol. 33, no. 11, pp. 1749-1754, 2003.

[24] A. A. Ramezanianpour, A. Pilvar, M. Mahdikhani and F. Moodi, "Practical evaluation of relationship between concrete resistivity, water penetration, rapid chloride penetration and compressive strength," J. Constr. Build. Mater., vol. 25, no. 5, pp. 2472-2479, 2011. 